\section{We may need to reconsider when to apply sunscreen in our daily life}

\author{
Win L Chiou* \\ Chiou Consulting Inc and Winlind Skincare LLC, Burr Ridge, Illinois 60527, USA
}

\section{Abstract}

Broad-spectrum sunscreens are now widely used worldwide as an adjunct to help prevent sunburn, skin cancers and premature skin aging. In the United States, all persons older than 6 months are recommended to apply sunscreen to all sun-exposed skin from toes to head except eyes and mouth even on cloudy days. Such a recommendation is apparently based on concepts that exposure to sunlight damages the skin, the damage is cumulative and hence any sun exposure should be minimized or prevented. This communication raises several questions suggesting that the above recommendation may need to be reconsidered. For example, numerous previous studies have indicated many potential health benefits from non-burning sun exposure including protection against sunburn, melanoma, colorectal cancer, breast cancer and prostate cancer, increasing vitamin D synthesis, helping sleep, reducing blood pressure, heart attack and stroke. Recent studies suggested that regular lifetime non-burning sun exposure may not result in premature skin aging and the skin aging is mainly caused by the intrinsic factor. Skin aging or whole-body aging has been recently postulated to be mainly attributed to a gradual reduction in cardiac output/index with age and a new anti-aging or age-reversing nutritional theory has been proposed. An apparent lack of long-term cumulative sunray damage was also supported by reported age independence in incidences of sunburn and skin cancers. It is of interest that the current US policy is different from that of World Health Organization and Australia recommending the need of sun protection only when UV Index is 3 or greater. In view of the above, some general guidelines regarding when to best apply sunscreen are proposed.

\section{More Information}

*Address for Correspondence: Win L Chiou, Chiou Consulting Inc and Winlind Skincare LLC, Burr Ridge, Illinois 60527, USA, Tel: 630789 9081; Email: win@chiouconsulting.com

Submitted: 20 September 2019

Approved: 21 October 2019

Published: 22 October 2019

How to cite this article: Chiou WL. We may need to reconsider when to apply sunscreen in our daily life. Ann Dermatol Res. 2019; 3: 007-010.

DOI: dx.doi.org/10.29328/journal.adr.1001007

Copyright: (c) 2019 Chiou WL. This is an open access article distributed under the Creative Commons Attribution License, which permits unrestricted use, distribution, and reproduction in any medium, provided the original work is properly cited.

Keywords: Sunscreens; Sunlight's benefits and risks; Skin cancers; Sunburn; Aging/antiaging theories; UV Index

(W) Check for updates

\section{Commentary}

Broad-spectrum sunscreens have been widely used as over-the-counter drugs in the United States, or as cosmetics in many other countries to help prevent sunburn, skin cancers and premature skin aging, i.e., photoaging. Currently the U.S. Food and Drug Administration (FDA) recommends that as an adjunct to other sun protection methods such as limiting time in the sun, especially between $10 \mathrm{AM}$ and $2 \mathrm{PM}$, seeking shade, wearing long-sleeved shirts, pants, broad-brimmed hats and sunglasses, we should liberally and evenly apply sunscreen to all sun-exposed areas of the body from toes to head except eyes and mouth for all persons older than 6 months even on cloudy days [1,2]. Such a policy is apparently based on concepts that exposure to sunlight damages the skin and the damage is cumulative [1-4]. Therefore, any sun exposure should be minimized or prevented.

The main purpose of this communication is to raise some questions regarding the above recommendations in view of (a) numerous past studies on potential health benefits of sunlight exposure including association of chronic and occupational sun exposure with low risks of skin cancers and sunburn in temperate countries, (b) a pivotal 1975 study reporting complete lack of effect of sun exposure on the contents of skin collagen, the major component of skin, in the lifetime of normal subjects, (c) a recent study indicating a lack of effect of sun exposure on the density decay kinetics of superficial nutritive capillaries, a critical skin tissue, over several decades of life span, (d) an unexpected exponential decay of skin collagen or capillaries with age apparently contradicting the conventional theory of accelerated aging, (e) reported studies indicating an age-independent incidences of skin cancers and sunburn and hence a lack of effect of cumulative non-burning sun exposure on skin cancer incidences, and (f) markedly different World Health Organization (WHO) and Australian recommendations on when to wear sunscreen in our daily life. The above questions will be briefly discussed and some recommendations on when to wear sunscreen will be proposed. It is hoped that this potentially provocative work may stimulate further discussions and studies on this important, timely subject.

In recent years, numerous studies on potential important health benefits of sun exposure have been reported ([5-8] 
and references therein). For example, contrary to common intuition, incidences of sunburn, melanoma and basal cell carcinoma have been found to be lower in general population with chronic sun exposure and also in outdoor professional workers (compared with indoor professional workers) in countries with temperate climate $[5,6,9,10]$. The lower incidences have been mainly attributed to increased skin thickness and darkening of skin color, our body's natural defense mechanism in response to external assaults from sunlight [11,12]. Sun exposure may also help prevent colorectal cancer, breast cancer, prostate cancer, nonHodgkin Lymphoma, multiple sclerosis, metabolic syndrome and bone fracture [5-8]. It can also benefit cardiovascular diseases (lowering blood pressure and reducing heart attack and stroke), Alzheimer disease, dementia, myopia, macular degeneration, obesity, insomnia, rheumatoid arthritis and diabetes [5-7]. It was reported that avoidance of sun exposure is a risk factor for all-cause death of the same magnitude as smoking [5,6,13]. Also, moderate sun exposure was associated with increased survival from melanoma [14]. Apparently because of insufficient exposure to sunlight, deficiency of vitamin $\mathrm{D}$ has been regarded as a potential serious public concern [5-8]. In recent years calls for a need to balance between the risks and benefits of sun exposure have been made $[5-7,15]$. In this regard, adequate sun exposure may be particularly important for elders [15].

Skin aging is mainly due to the body's intrinsic factor and the environment's extrinsic factors, such as sunrays and air pollution. Photoaging caused by sun has been commonly assumed to account for up to $80 \%$ to $90 \%$ of the total skin aging $[16,17]$. Ultraviolet (UV) radiation from the sun, for example, has been shown $[3,17,18]$ to reduce the synthesis and increase the degradation of collagen, the major component of skin. The work of Schuster, et al. [19] surprisingly, reported completely different results that the collagen contents from skin specimens taken from sun-exposed and sun-protected areas in a large number of subjects over a wide range of age were the same; not being lower in sun-exposed areas as anticipated from the conventional photoaging theory [20].

Published density data of superficial nutritive capillaries from subjects in a wide range of age [21] have been recently reanalyzed based on first-order kinetics [20]. The decay slopes from sun-exposed and sun-protected areas were found to be virtually identical indicating again an apparent lack of effect of sun exposure on the aging of this skin component [20]. The above collagen and capillary data may suggest that daily exposure to mild or moderate sunlight may not significantly contribute to skin aging, normal skin aging is mainly due to the intrinsic factor, and sunscreen may not be needed for such a purpose [20]. Obviously, exposure to intense or burning sunlight should be avoided as it may accelerate skin aging and cause sunburn and skin cancers.

Interestingly, the above observed exponential decay of skin collagen contents and skin capillary densities appeared to contradict the conventional acceleration theory of skin aging [20]. These unexpected aging phenomena were also found to occur in human hearts [20].

The above findings of apparent lack of effect of sun exposure on skin aging and skin damage may be primarily attributed to extremely effective repair mechanisms of the body [20]. For example, various degrees of sunburn can usually be completely healed within weeks after only minor intervention $[20,22]$. UV-damaged DNA in skin can be virtually completely repaired within days or weeks $[16,23,24]$. DNA damage after UV radiation of erythemal or sub-erythemal dose could be fully recovered in weeks by either repairing the damage or eliminating or replacing the damage [23,24]. Interestingly, our body seems to constantly maintain a delicate balance of normal cells and mutated cells in a homeostatic state $[23,24]$. The above discussion further suggests that most or virtually all photo damage of DNA, RNA or proteins may be only temporary and not be cumulative in the long run as commonly assumed.

Contrary to some classical theories, It has been postulated that aging signs such as thinning, sagging, fine lines, mild wrinkles, and age spots may be primarily attributed to reduced delivery of nutrients via skin tissue capillaries [25] due to reduced cardiac output with age, our body's natural defense mechanism, or born and/or acquired deficiencies in skin microcirculation [20]. It is encouraging that some potential implications of the recent cardiac- output/nutrition aging theory [20] have been confirmed. For example, simple rejuvenation of hearts in old rats by progenitor-like cells was found to quickly result in the repair of the heart structure and the unexpected systemic tissue/organ rejuvenation making the old rats appear much younger and energetic [26], this in turn may prolong the rat's healthy lifespan [20], more importantly, this was in fact an age-reversing phenomenon. Also, topical application of high concentrations of propylene glycol, a calorie-generating nutrient, in water was found to be able tos quickly regenerate or accelerate the growth of a variety of tissues such as nail, hair and gum in humans apparently through its rejuvenation of tissue's stem/progenitor cells [27].

If the detrimental effect of sunlight on skin is cumulative over years, in theory, one should expect that the incidence of melanoma would increase with age. However, this apparently is not the case as melanoma incidences were found to be ageindependent $[5,6,9]$. Furthermore, regardless of age, five or more sunburns were found to almost double the chance of getting melanoma [9]. Also, melanoma was found to occur most often on the back of the body where usually received sunlight protection from clothing, except during intense intermittent sun exposure that may cause sunburn [22]. The reports on effect of age on the development of basal cell carcinoma and squamous cell carcinoma have been less consistent [5] However, a more recent review has concluded that measured 
long-term or total sun exposure had no association with their occurrences [5,29]. As expected, the incidences of sunburn, a quickly identifiable acute skin lesion, were also age-independent $[5,29]$. The above discussion may suggest that contrary to conventional concepts, daily exposure to nonburning, mild or moderate sunlight may only play a relatively minor role in the development of skin cancers and sunburn.

The WHO has earlier developed guidelines on the use of an ultraviolet index (UVI), a measure of the level of UV radiation [30]. The values of the index range from zero upward-the higher the UVI, the greater the potential for damage to the skin and eyes, and the less time it takes for harm to occur. Sunlight with a UVI up to 2 is classified as low solar intensity and people can safely enjoy being outside since the risk is limited. UV Indexes between 3 and 5 are moderate in intensity requiring sun protection measures. UV Indexes 6 and 7 are regarded as high intensity, 8 to 10 very high intensity, and 11 or higher extreme intensity. The above WHO guidelines are apparently not adopted in the U.S. and most other countries. Surprisingly, these guidelines were adopted in 2014 in Australia, that has one of the highest incidences of melanoma in the world [31]. Since then Australians have been apparently enjoying sunshine without wearing sunscreen and without using other protective measures for the skin when the UVI is below 3. Furthermore, physicians there were prescribing daily sunshine for treating vitamin D deficiency [31].

In view of the above discussions, I would like to propose the following for possible consideration by our health authorities:

1. Inform the public of potential important health benefits from daily exposure to mild or moderate non-burning sunlight, including lowering the risks of skin cancers and sunburn, while emphasizing the danger of getting sunburned from over- exposure or from improperly using sunscreens.

2. Inform the public that in general daily exposure to mild or moderate non-burning sunlight may not significantly contribute to incidences of premature or early skin aging, sunburn and skin cancers, and that wearing of sunscreen may instead deprive users of potential health benefits from the sun exposure.

3. The need of degree of sun protection may vary significantly with many factors such as race, skin type, skin location, UV Index, length of sun exposure and latitude $[1,2,6]$. Thus, some general guidelines regarding the meaning of mild or moderate non-burning sun exposure may need to be developed. In the interim the current WHO guidelines may be totally or partially adopted. Unlike Australia where most residents are white with sun-sensitive skin, the US has a very large segment of non-white, less skin-sensitive population such as African, Mexican and Asian descents. Therefore, the recommended UV Index requiring sun protection for non-white residents may need to be adjusted upward such as 4 to $6^{* * *}$

\section{*** Limited personal experiences}

I, an Asian at age 81, have been exposed for about 30 to 60 minutes each day to sunlight with UVI of 6 or 7 for 24 days in a two-month period in Chicago in the last year. My body was only covered with short pants, a pair of sunglasses and sneakers and I have never developed any skin discomfort and sunburn. More recently I was similarly exposed to sunlight with UVI of 9 for 30 minutes without getting sunburned except with some very slight pink or darkened areas on the back and front of the body that have never been directly exposed to sunlight in the last 6 decades except last year.

\section{References}

1. USA FDA website: Tips to stay safe in the sun: From sunscreen to sunglasses.

2. Guerra KC, Crane JS. Skin cancer prevention. StatPearls (Internet) Treasurelsland (FL). 2019.

PubMed: https://www.ncbi.nlm.nih.gov/books/NBK519527/

3. Fisher GL, Datta SC, Talwar HS, Wang ZQ, Varani J, et al. Molecular basis of sun-induced premature skin ageing and retinoid antagonism. Nature. 1996; 379: 335-339.

PubMed: https://www.ncbi.nlm.nih.gov/pubmed/8552187

4. Nole G, Johnson AW. An analysis of cumulative lifetime solar ultraviolet radiation exposure and the benefits of daily sun protection. Dermatol Ther. 2004; 17: 57-62.

PubMed: https://www.ncbi.nlm.nih.gov/pubmed/14728700

5. Hoel DG, Berwick M, de Gruijl FR, Holick MF. The risks and benefits of sun exposure 2016. J Dermato- Endocrinol. 2016; 8: E1248325.

PubMed: https://www.ncbi.nlm.nih.gov/pubmed/27942349

6. Rhee HVD, de Vries E, Coomans $C$, van de Velde $P$, Coebergh JW Sunlight for better or for worse? A review of positive and negative effects of sun exposure. Cancer Res Frontiers. 2016; 2: 156-183.

7. Grant WB. A review of the evidence supporting the vitamin D-cance prevention hypothesis in 2017. Anticancer Res. 2018; 38: 1121-1136. PubMed: https://www.ncbi.nlm.nih.gov/pubmed/29374749

8. Valles X, Alonso MH, López-Caleya JF, Díez-Obrero V, Dierssen-Sotos $\mathrm{T}$, et al. Colorectal cancer, sun exposure and dietary vitamin $\mathrm{D}$ and calcium intake in the MCC-Spain study. Environ Int. 2018; 121: 428-434. PubMed: https://www.ncbi.nlm.nih.gov/pubmed/30266013

9. Gandini S, Sera F, Cattaruzza MS, Pasquini P, Picconi O. Meta-analysis of risk factors for cutaneous melanoma: II. Sun exposure. Eur J Cancer. 2005; 41: 45-60.

PubMed: https://www.ncbi.nlm.nih.gov/pubmed/15617990

10. Planta MB. Sunscreen and melanoma: Is our prevention message correct? J Amer Board Med. 2011; 24: 735-739.

PubMed: https://www.ncbi.nlm.nih.gov/pubmed/22086817

11. Winter SD, Vink AA, Roza L, Pavel S. Solar-stimulated sun adaptation and its effect on subsequent UV-induced epidermal DNA damage. J Invest Dermatol. 2001; 117: 678-682.

PubMed: https://www.ncbi.nlm.nih.gov/pubmed/11564176

12. Brenner M, Hearing VJ. The protective role of melanin against UV damage in human skin. Photochem Photobio. 2008; 84:539-549. PubMed: https://www.ncbi.nlm.nih.gov/pmc/articles/PMC2671032/

13. Lindqvist $P G$, Epstein $E$, Landin-Olsson $M$, Ingvar $C$, Nielsen $K$, et al Avoidance of sun exposure is a risk factor for all- cause mortality results from the melanoma in southern Sweden cohort. J Intern Med. 
2014; 276: 77-86.

PubMed: https://www.ncbi.nlm.nih.gov/pubmed/24697969

14. Berwick M, Armstrong BK, Ben-Porat L, Fine J, Kricker A, et al. Sun exposure and mortality from melanoma. J National Cancer Inst. 2005; 97: 195-199.

PubMed: https://www.ncbi.nlm.nih.gov/pubmed/15687362

15. Wright F. Weller RB, Risks and benefits of UV radiation in older people: More of a friend than a foe? Maturitas. 2015; 81: 425-431.

PubMed: https://www.ncbi.nlm.nih.gov/pubmed/26049767

16. Taylor CR, Stern RS, Leyden JJ, Gilchrest BA. Photoaging/photodamage and photoprotection. J Amer Acad Dermatol. 1990; 22: 1-15.

PubMed: https://www.ncbi.nlm.nih.gov/pubmed/2405022

17. Kammeyer A, Luiten RM. Oxidation events and skin aging. Ageing Res Rev. 2015; 21: 16-29.

PubMed: https://www.ncbi.nlm.nih.gov/pubmed/25653189

18. Quin T, Qin Z, Xia W, Shao Y, Voorhees JJ, et al. Matrix-degrading metalloproteinases in photoaging. J Invest Dermatol. 2009; 14: 20-24. PubMed: https://www.ncbi.nlm.nih.gov/pubmed/19675548

19. Shuster S, Black MM, McVitie E. The influence of age and sex on skin thickness, skin collagen and density. Br J Dermatol. 1975; 93: 639-643. PubMed: https://www.ncbi.nlm.nih.gov/pubmed/1220811

20. Chiou WL. Aging kinetics of human hearts and skin: New aging theories and implications in the use of sunscreens. Dermatol Arch. 2017; 1: 1-5.

21. Li L, Mac-Mary S, Sainthillier JM, Nouveau S, de Lacharriere O, et al. Age-related changes of the cutaneous microcirculation in vivo. Gerontology. 2006; 52: 142-153.

PubMed: https://www.ncbi.nlm.nih.gov/pubmed/16645294

22. Habif HP. Clinical Dermatology, 5th ed. 2010, MOSBY, Elsevier. Pages 747 and 863.
23. Anna B, Blazej Z, Jacqueline G, Andrew CJ, Jeffrey R, et al. Mechanism of UV-related carcinogenesis and its contribution to nevi/melanoma. Expert Rev Dermatol. 2007; 2: 451-469.

PubMed: https://www.ncbi.nlm.nih.gov/pmc/articles/PMC2564815/

24. Scott TL, Blazej Z, Jacqueline G, Andrew CJ, Jeffrey R, et al. Repair of oxidative DNA damage and cancer: Recent progress in DNA base excision repair. Antioxid Redox Signal. 2014; 20: 708-726.

25. Chiou WL. The phenomenon and rationale of marked dependence of drug concentrations on blood sampling site (part 1), Clin Pharmacokin. 1989; 7: 175-199.

PubMed: https://www.ncbi.nlm.nih.gov/pubmed/2680213

26. Grignorian-Sharmagian L. Liu W, Fereydooni S, Middleton RC, Valle J, et al. Cardiac and systemic rejuvenation after cardiosphere-derived cell therapy in senescent rats. Eur Heart J. 2017; 38: 2957-2967. PubMed: https://www.ncbi.nlm.nih.gov/pubmed/29020403

27. Chiou WL. Compositions and methods for tissue regeneration. United States. Patent No: US 10,456,366 issued on Oct. 29, 2019.

28. Lin JS, Eder M, Weinmann S. Behavioral counseling to prevent skin cancer: A systematic review for the U.S. Preventative Services Task Force. Ann Intern Med. 2011; 154: 190-201. PubMed: https://www.ncbi.nlm.nih.gov/pubmed/21282699

29. Armstrong BK, Kricker A. The epidemiology of UV induced skin cancer. J Photochem Photobiol 2001; 63: 8-18.

PubMed: https://www.ncbi.nlm.nih.gov/pubmed/11684447

30. Website for WHO UV Index accessed on September 6, 2019.

31. Seigel $\mathrm{J}$, America is getting the science of sun exposure wrong. Website for Cancer Council Australia (2014). 2019. 